\title{
The benefits of $k$-Carrageenan-gelatin hybrid composite coating on the medical grade stainless steel (SS304) used as anticorrosive barrier
}

\author{
L.Muthulakshmi ${ }^{\mathrm{a}, \mathrm{b} *}$, B.Anand Kumar ${ }^{\mathrm{c}}$, Aruliah Rajasekar ${ }^{\mathrm{d}}$, J.Annaraj ${ }^{\mathrm{a} *}$, Catalin I. Pruncu ${ }^{\mathrm{e}, \mathrm{f}^{*}}$ \\ a Department of Materials Science, School of Chemistry, Madurai Kamaraj University, \\ Madurai, 625021 Tamil Nadu, India.
}

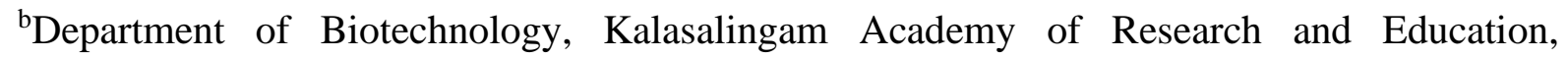
Krishnankoil -626 126, India.

${ }^{\mathrm{c}}$ Metallurgy and Materials Group, Indira Gandhi Center for Atomic Research, Kalpakkam 603102, India.

${ }^{\mathrm{d} E n v i r o n m e n t a l}$ Molecular Microbiology Research Laboratory, Department of Biotechnology, Thiruvalluvar University, Serkkadu, Vellore 632 115, Tamil Nadu, India.

e Department of Mechanical Engineering, Imperial College London, Exhibition Rd., London, UK

${ }^{\mathrm{f} D e s i g n}$, Manufacturing \& Engineering Management, University of Strathclyde, Glasgow, G1 1XJ, Scotland, UK.

Corresponding author: catalin.pruncu@strath.ac.uk ； c.pruncu@imperial.ac.uk ; 1.muthulakshmi@klu.ac.in ; jjannaraju@gmail.com

\begin{abstract}
Biopolymers derived from seaweed are good anticorrosive, antibacterial and anticancer agents. These biopolymers family includes the $\boldsymbol{k}$-Carrageenan with good potential anticorrosive feature that is extracted from the red seaweed Acanthophora spicifera Rhodophyceae. To obtain the best corrosion inhibition properties the $\boldsymbol{k}$-Carrageenan hybrid composite with gelatin was prepared by sol-gel method. In the present study, two natural compounds have been used to prepare the proposed hybrid composite material. Such as, a self-assembled multilayer coating for medical grade stainless steel (SS) 304 were formed as substrate which can resist successfully to mild condition ( 3.5 wt $\%$ of $\mathrm{NaCl}$ ) in the chosen electrolyte medium. The analysis by FT-IR confirms the hybridation of gelatin and biopolymer of $k$-Carrageenan. The electrochemical results revealed that the coated SS 304 is a promising corrosion inhibition with an efficiency up to $97 \%$ at $24 \mathrm{~h}$ and up to $65 \%$ at $227 \mathrm{~h}$. The $E_{o c}$ values from open circuit potential analysis indicated the occurrence of passivation on the surface due to hybrid composite coating. Further, the electrochemical impedance spectroscopy showed that the resistance of hybrid composite is higher than the bare steel showing $R_{\mathrm{ct}}$ of $6.1 \mathrm{k} \Omega \cdot \mathrm{cm}^{2}$ and $2.1 \mathrm{k} \Omega \cdot \mathrm{cm}^{2}$, respectively. The microstructural analysis by
\end{abstract}


Scanning Electron Microscopy (SEM) and atomic force microscopy (AFM) confirmed that the coating surface have better corrosion resistance than SS 304 bare metal.

Keywords: $\boldsymbol{k}$-Carrageenan; Red seaweed; gelatin; hybrid composite; stainless steel; corrosion inhibition.

\section{Introduction}

Protection of metal surfaces from corrosion by coating with polymeric hybrid/composite materials is consistent and efficient way of providing an impenetrable obstacle to the metal surface from water and other related corrosive species [1]. Solid adsorption of hybrid/composite materials on the active sites of metal surfaces can efficiently diminish the possibility of oxidation process by forming a protective film on their surface [2]. In this regard, the naturally occurring polysaccharides/biopolymers existing as the products of biochemical progressions in living systems [3]. Seaweeds signify a widely used source of different polysaccharides, well known in the industry for their food and sensor applications [4 ,5]. Red seaweeds produce carrageenans, agars, and variants, used in a manifold of industries as gelling and thickening agents. Polysaccharides, such as $\boldsymbol{k}$-Carrageenans have significant industrial and biomedical relevance and shown several biological applications. Most importantly, 1 -Carrageenan and $\kappa$-Carrageenan are also used in water-based paints due to their ability to prevent the settling of particles [6]. Recent reports state that the natural polymers have started to gain tremendous attention in corrosion inhibition due their availability, biocompatibility, non-toxicity and inexpensiveness [7, 8]. Such biopolymers, like $\boldsymbol{k}$-Carrageenan can form complexes with metals by several active $\mathrm{O}$ donors in its heterocyclic rings which eventually shield metal surface from contact to corrosive medium [9]. Stainless steel 304 is widely used in many sectors of industry due to its high corrosion resistance and reusability [10]. The medicinal grade stainless steel is commonly employed as biomaterial in orthopaedic implants. Surface of SS304 can be modified to achieve antimicrobial feature by applying biopolymers through dip coating, brush coating or sol-gel coating [11].

Though several coating methods have been reported for improving the surface modification, especially conducting polymer coatings are continuously showing a great improvement for protection of metal surfaces $[12,13]$ due to their strong oxidizing capability, the passivation of steel could be facilitated [14]. Significant numbers of environmentally friendly polysaccharides especially based on Inulin and family of Carrageenan have been published as polymeric corrosion inhibitors towards investigated for mild steel in 0.5 
$\mathrm{mol} / \mathrm{dm}^{3} \mathrm{H}_{2} \mathrm{SO}_{4}$ [15]. The naturally available biopolymers have been utilized as an insulating layer to protect the metals from corrosion and preventing the electron transfer from the metal surfaces [16]. The $\boldsymbol{k}$-Carrageenan derived from red algae, Acanthophora spicifera, consists of three hydroxyl and one sulfate groups. Its structure may bind with the metals and form complexes [17]. This green corrosion inhibitor can be combined with gelatin, known from good barrier properties, to provide enhanced corrosion resistance.

In the present work, corrosion inhibition as a hybrid conjugate between biomolecules of $\boldsymbol{k}$ Carrageenan and gelatin was developed. Then, the formed coating barrier on the surface of SS304 were subjected to the mild electrolyte environment of $3.5 \mathrm{wt} . \% \mathrm{NaCl}$. Corrosion rate and the inhibition efficiency were determined using electrochemical techniques. The surface degradation of the polymer coated SS304 was examined using scanning electron microscopy (SEM) and atomic force microscopic (AFM) techniques. The results gathered in this research are paramount important in the biomedical field in which the corrosion degradation play an important role.

\section{Materials and Methods}

\subsection{Materials collection}

The red seaweed Acanthophora spicifera was collected at Central Marine Fisheries Research Institute, Mandapam region of Ramanathapuram district, (lies between $9^{\circ} 5^{\prime}$ and $9^{\circ} 5^{\prime}$ North Latitude and $78^{\circ} 1^{\prime}$ and $79^{\circ} 27^{\prime}$ East Longitude) Tamil Nadu, India. The medical- grade stainless steel (SS304) (chemical composition of SS0304 (wt. \%) Cr-18.18\%, Si-0.57\%,Mn$1.75 \%, \mathrm{P}-0.028 \%$, C-0.051\%, Ni-8.48\%, N-0.05\%, S-0.005\%, Fe-70.886\%) was purchased from Alfa-Aesar, Thermo Fisher Scientific India (P) Ltd, Mumbai, India. Gelatin, NaCl, and emery sheets (300-1000 grit) of GR grade were procured from Sigma Aldrich, India.

\subsection{Extraction of $k$-Carrageenan polymer}

The collected red seaweed was subjected to the initial purification process: 1. washing in the running to elucidate the adsorped impurities such as salt and sand; 2. cleaning with the distilled water; 3. air dry. Once seaweed is dried, it was grounded to a fine powder using mortar and pestle. The grounded algae were treated with a mixture of $20 \%(\mathrm{~V} / \mathrm{V})$ acetone and $80 \%(\mathrm{~V} / \mathrm{V})$ ethanol to remove hydrophobic and hydrophilic pigments. About $100 \mathrm{~g}$ of the purified seaweed was heated in $1000 \mathrm{~mL}$ of water at an alkaline $\mathrm{pH}(8-9)\left(0.5 \mathrm{~mol} / \mathrm{dm}^{3}\right.$ $\mathrm{NaHCO}_{3}$ ) solution in a water bath at $90^{\circ} \mathrm{C}$ for $3 \mathrm{~h}$, the existing insoluble residues were 
removed by filtration. The filtered solution was precipitated with excess ethanol and dried at RT for $24 \mathrm{~h}$, further grinded into fine powder yield $5 \mathrm{~g}$ of $\boldsymbol{k}$ - Carrageenan powder [18].

\subsection{Carrageenan-gelatin coating Preparation}

The $\boldsymbol{k}$-Carrageenan-gelatin hybrid composite was prepared by the sol-gel method. The $\boldsymbol{k}$ Carrageenan solution was prepared by dissolving $1 \mathrm{~g}$ of carrageenan powder in $10 \mathrm{~mL}$ of Milli-Q water kept under stirring for 30 minutes at $40^{\circ} \mathrm{C}$ at $700 \mathrm{rpm}$ on a hot plate stirrer using a magnetic stirrer bar. Similarly, dissolving $1 \mathrm{~g}$ of gelatin granules in $10 \mathrm{~mL}$ of Milli-Q water at $50^{\circ} \mathrm{C}$ with constant stirring at $600 \mathrm{rpm}$ for 30 minutes. The cross-linker was prepared by mixing $1 \mathrm{~mL}$ of glutaraldehyde in ethanol with $0.1 \mathrm{~mL}$ of $\mathrm{HCl}(0.01 \mathrm{~N})$. The above two solutions were blended with the addition of the cross-linkers at $45^{\circ} \mathrm{C}$ for 20 minutes by magnetic stirring at $200 \mathrm{rpm}[19,20]$.

\subsection{Electrochemical Measurements}

The SS304 surface $(10 \mathrm{~mm} \times 10 \mathrm{~mm} \times 3 \mathrm{~mm})$ was abraded with a series of emery papers (grade from 300-1200) and wash with water and acetone. $100 \mu l$ of $\boldsymbol{k}$-Carrageenan - gelatin composite was formed on the SS 304 surface $(10 \mathrm{~mm}$ x $10 \mathrm{~mm})$ with a thickness of $0.5 \mathrm{~mm}$ using self-assembled multiple layer film by brush coating method [21, 22]. The enhancing barrier properties of the hybrid composite coating on SS304 were analyzed up to $227 \mathrm{~h}$ in a 3.5 wt $\% \mathrm{NaCl}$ electrolyte solution. The corrosion studies were performed on $\mathrm{CHI} 760-\mathrm{CH}$, USA Instruments. The three- electrode setup, $\mathrm{Ag} / \mathrm{AgCl}(3 \mathrm{M} \mathrm{KCl}), \mathrm{Pt}$ wire and the biopolymer coated SS304 were used as a reference, counter, and working electrodes respectively. The test specimen $(10 \mathrm{~mm} \times 10 \mathrm{~mm})$ was immersed in $3.5 \mathrm{wt} \% \mathrm{NaCl}$ corrosive environment further, the standard corrosion tests including open circuit potential measurements $\left(E_{o c}\right)$, electrochemical impedance spectroscopy (EIS) and Tafel polarization experiments. ASTM D 570- 98 standard was carried out to evaluate the corrosion inhibition efficiency. Further, the corrosion protection efficiency ( $\eta \%)$ of coated SS 304 metal was determined as in the earlier report [23]. The surface coverage was calculated by the formula described earlier in [24]. The corrosion rate of bare and coated SS304 was calculated by the following formula. 


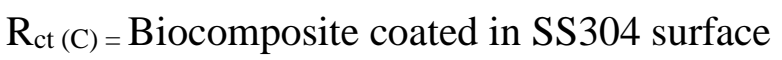

$\mathrm{R}_{\mathrm{ct}(\mathrm{B})=}$ Bare SS304 surface

\subsection{Surface analysis}

FT-IR spectral analysis was carried out (Shimadzu - IR Tracer-100) to confirm the functional group of $\boldsymbol{k}$-Carrageenan and gelatin biopolymers in the hybrid composite.

\subsubsection{SEM and AFM Analysis}

The surface characterization of SS304 $(10 \mathrm{~mm} \times 1 \mathrm{~mm} \times 3 \mathrm{~mm})$ before and after the experiment coating with biocomposite and uncoated were fully immersed in $3.5 \mathrm{wt} \% \mathrm{NaCl}$ for $227 \mathrm{~h}$. The steel specimen was removed washed with distilled water and dried before the microscopic analysis. The scanning electron microscopy (VEGA3 TESCAN model) and Atomic force microscopy nanosurf ECSCAN 2 the model with cantilever ContAl-G Switzerland.

\section{Results and Discussion}

\subsection{FT-IR spectra of $k$-Carrageenan-gelatin}

Figure 1 shows the FT-IR spectrum of $\boldsymbol{k}$-Carrageenan and gelatin. The presence of sulfated polysaccharide indicates the stretching vibration at $1184 \mathrm{~cm}^{-1}$ [25]. The vibrational band at $3466 \mathrm{~cm}^{-1}$ confirms the presence of the hydroxyl group in the biopolymer carrageenan [26]. The band at $849 \mathrm{~cm}^{-1}$ is assigned to the existing moiety in D-galactose-4-sulphate and 3,6anhydrous-D-galactose [27]. Figure $1 \mathrm{~b}$ displays the absorption peak at $3429 \mathrm{~cm}^{-1}$ and 3404 $\mathrm{cm}^{-1}$ attributed to $\mathrm{N}-\mathrm{H}$ stretching vibrations of the amide group in gelatin, which is closely comparable with the previously reported pure gelatin [28,29]. The $\mathrm{C}-\mathrm{H}$ stretching band is observed at $2923 \mathrm{~cm}^{-1}$. The appeared sharp band at $2854 \mathrm{~cm}^{-1}$ is attributed to the S-H stretching vibration band indicating the thiol group. The strong band observed at $1635 \mathrm{~cm}^{-1}$ may be assigned to $\mathrm{C}=\mathrm{C}$ stretching vibrations [30]. 

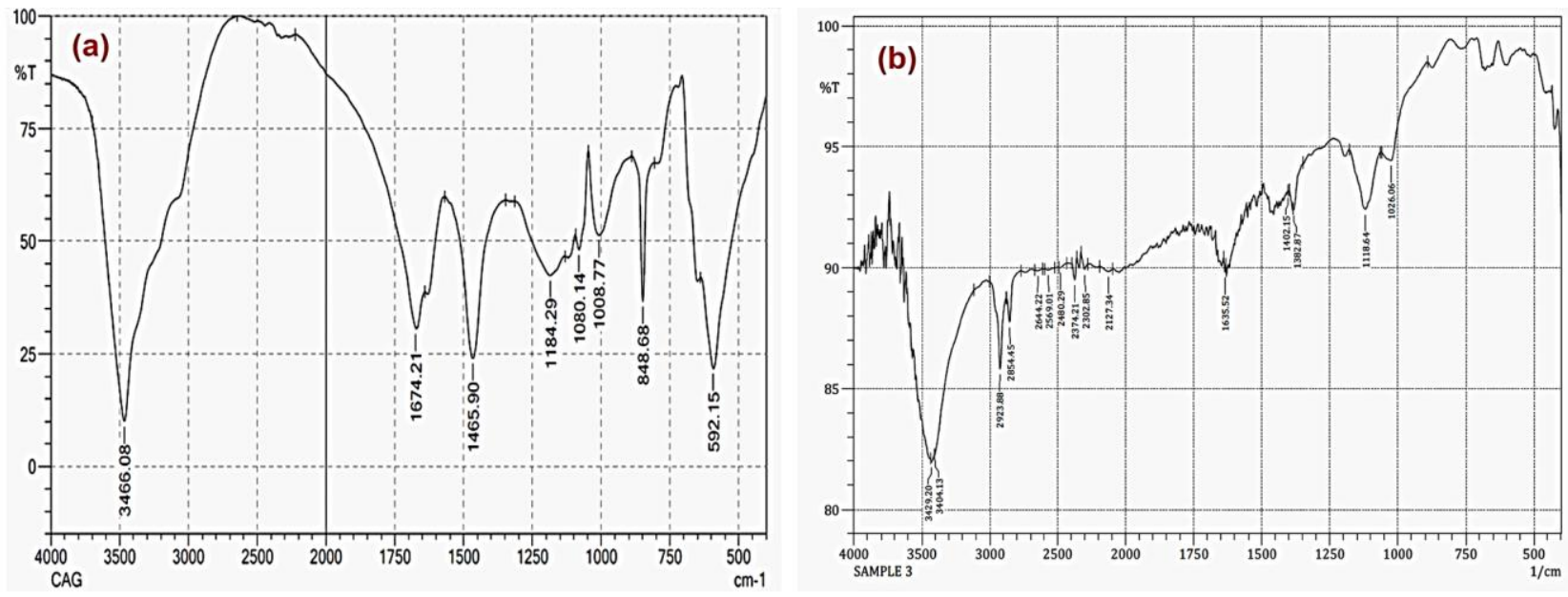

Fig.1. FTIR spectra of (a). Seaweed extracted carrageenan polymer and (b) gelatin

\subsection{Electrochemical analysis}

The comparable preliminary $\mathrm{E}_{\mathrm{oc}}$ and representative Tafel and EIS data towards bare SS304 are shown in Figure 2. The observed variation in $\mathrm{E}_{\mathrm{oc}}$ may due to surface passivation (more positive $\mathrm{E}_{\mathrm{oc}}$ ) and its subsequent rupture (negative $\mathrm{E}_{\mathrm{oc}}$ ). This positive $\mathrm{E}_{\mathrm{oc}}$ of the biocomposite coated film with respect to bare SS, suggested that the coating enable a better resistance to corrosion inhibition.

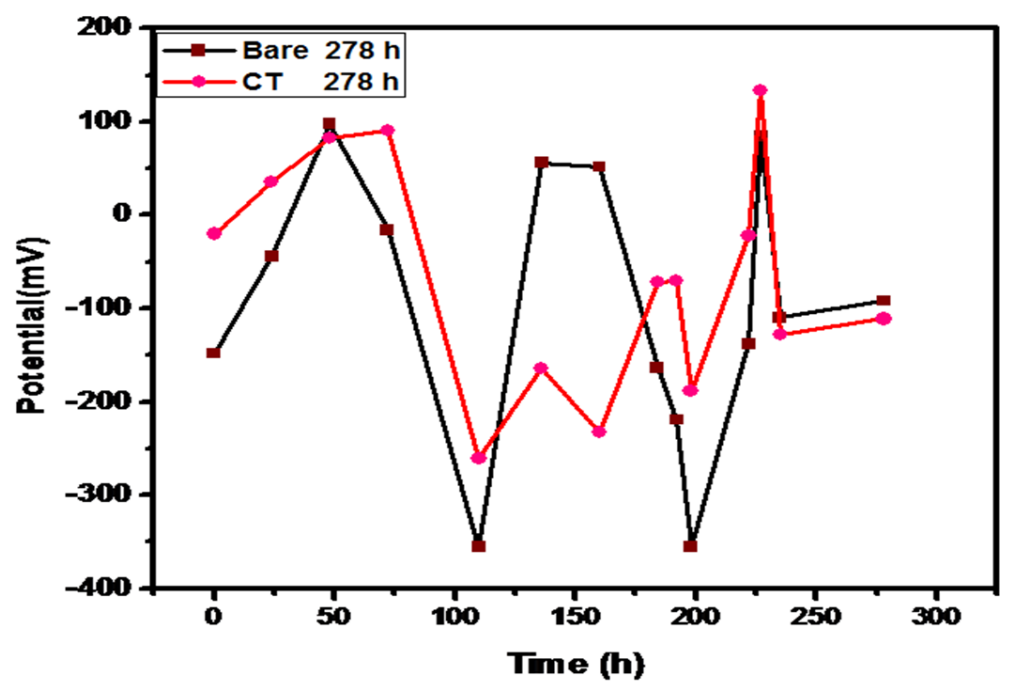

Fig.2. Open circuit potential $\left(\mathrm{E}_{\mathrm{oc}}\right) v s$ time for bare SS and biocomposite coated SS at $278 \mathrm{~h}$

This analysis helped us to identify the most favourable conditions for bare SS 304 which is at $47 \mathrm{~h}(98 \mathrm{mV})$ and $135 \mathrm{~h}(53 \mathrm{mV})$ and for biocomposite coated SS. However, considering the magnitude, the biocomposite has a more positive $\mathrm{E}_{\mathrm{oc}}(134 \mathrm{mV})$ than bare $\mathrm{SS}(82 \mathrm{mV})$ at 227 
h. Further variations observed in $E_{o c}$ towards negative potentials for coated SS 304 at $136 \mathrm{~h} \mathrm{(-}$ $166 \mathrm{mV}$ ) and $58.3 \mathrm{mV}$ for bare SS. for biocomposite coated surface suggested the occurred rupture and breakdown of the passive film, again the passivation was noted on the biopolymer coated film at $190 \mathrm{~h}(-70.8 \mathrm{mV})$ compared to the bare SS304 $(-219 \mathrm{mV})$ [31]. The variation of $E_{o c}$ with respect to time is shown in (Figure 2). It may be noted that the $E_{o c}$ values of both bare SS and biocomposite coated SS showed a periodic variations in both positive and negative directions, suggested that the continuous passivation by forming a film on the surface and its subsequent failure, and such behaviour is very common in SS surface [32]. The rapid and random variations in $\mathrm{E}_{\mathrm{oc}}$ may be attributed to the percolation of the electrolyte ions (chloride ions) into the interface, which is likely to be promoted by the porosity of $\boldsymbol{k}$-Carrageenan-gelatin hybrid composite coating on SS. However, observing the trend in the variation (Figure. 2) and based on the sign and magnitude of $E_{o c}$, the biopolymer/SS composite showed a more positive values of $-22 \mathrm{mV}$ at $0 \mathrm{~h}$, and $134 \mathrm{mV}$ at $227 \mathrm{~h}$ than bare SS at $0 \mathrm{~h}(-148 \mathrm{mV})$ and $227 \mathrm{~h}(82 \mathrm{mV})$ [33]. The detailed information about cathodic and anodic tafle slopes, polarization resistance and corrosion rate of bare and composite coated samples at different times 0 h, 24 h, 96 h, $192 \mathrm{~h}$ and $227 \mathrm{~h}$ were presented in Table 1 and Table 2.

Table 1. Electrochemical data for the biocomposite coated SS304 and Bare SS 304 in 3.5 wt \% of $\mathrm{NaCl}$ as electrolyte

\begin{tabular}{|c|c|c|c|c|c|c|c|}
\hline $\begin{array}{ll}\text { S.No } & \text { Time } \\
\text { (h) }\end{array}$ & $\begin{array}{l}\text { Bare } \\
\text { /Coated }\end{array}$ & $\begin{array}{l}\mathbf{E}_{\text {corr }} \\
(\mathrm{mV}\end{array}$ & $\begin{array}{l}\mathbf{I}_{\text {corr }} \\
\left(\mathrm{A} \mathrm{cm}^{-2}\right)\end{array}$ & $\begin{array}{l}\text { Bc } \\
(\mathrm{mV} / \mathrm{dec})\end{array}$ & $\begin{array}{l}\beta \mathbf{a} \\
(\mathrm{mV} / \mathrm{dec})\end{array}$ & $\begin{array}{l}R_{P} \\
\text { cm-2) }\end{array}$ & $\begin{array}{l}\mathrm{C}_{\mathrm{R}} \\
\text { (mmpy) }\end{array}$ \\
\hline \multirow[t]{2}{*}{ 1. 0} & B & 188 & $3149 \times 10^{-3}$ & 1007 & 8836 & 124649 & 10.01 \\
\hline & $\mathrm{C}$ & 408 & $1821 \times 10^{-3}$ & 2809 & 6651 & 470916 & 5.79 \\
\hline \multirow[t]{2}{*}{ 2. 24} & B & 162 & $1746 \times 10^{-3}$ & 3081 & 199 & 464871 & 5.55 \\
\hline & $\mathrm{C}$ & 269 & $2691 \times 10^{-4}$ & 260 & 455 & 2669 & 8.55 \\
\hline \multirow[t]{2}{*}{ 3. 96} & $\mathrm{~B}$ & 591 & $1286 \times 10^{-3}$ & 4391 & 4855 & 792059 & 4.08 \\
\hline & $\mathrm{C}$ & 165 & $1277 \times 10^{-3}$ & 814 & 7537 & 253576 & 4.06 \\
\hline \multirow[t]{2}{*}{ 4. 192} & $\mathrm{~B}$ & 484 & $5487 \times 10^{-3}$ & 3131 & 6047 & 8055 & 17.44 \\
\hline & $\mathrm{C}$ & 638 & $2190 \times 10^{-3}$ & 834 & 5361 & 1430 & 6.96 \\
\hline \multirow[t]{2}{*}{ 5. 227} & $\mathrm{~B}$ & 302 & $8753 \times 10^{-4}$ & 1948 & 6590 & 476.8 & 27.8 \\
\hline & $\mathrm{C}$ & 653 & $8108 \times 10^{-4}$ & 3943 & 4776 & 1628 & 25.7 \\
\hline
\end{tabular}
B. Bare SS304 specimen
C- Biocomposite coated SS304 specimen 
Table.2 Electrochemical impedance parameters for bare SS 304 and biocomposite coated SS304 in 3.5 wt \% $\mathrm{NaCl}$ electrolyte.

\begin{tabular}{|c|c|c|c|}
\hline $\begin{array}{l}\text { Time } \\
\text { (h) }\end{array}$ & $\begin{array}{c}\mathbf{R}_{\mathrm{ct}} \text { (Bare) } \\
\quad \boldsymbol{\Omega} \mathbf{c m}^{2}\end{array}$ & $\begin{array}{l}R_{\mathrm{ct}}(\text { coated) } \Omega \\
\mathrm{cm}^{2}\end{array}$ & $\%$ IE \\
\hline 0 & 94.8 & 223.8 & 57.65 \\
\hline 24 & 25.84 & 1238 & 97.91 \\
\hline 96 & 48.03 & 327.8 & 85.34 \\
\hline 192 & 473.42 & 1052 & 55.98 \\
\hline 227 & 2141 & 6035 & 64.52 \\
\hline
\end{tabular}

\subsection{Potentiodynamic polarization curve}

The anodic and cathodic tangent were observed in Tafel plot. The multilayer biocomposite coating could be effectively sealed the pores and protects the surface of SS304, which was shown in Tafel data, as illustrated in Figure 3b, the detailed cathodic and anodic protection results have been reported in the presence and absence of biocomposite coating. The more favourable shift in $\mathrm{E}_{\text {corr }}$ values towards positive direction for the biocomposite coated SS ($269 \mathrm{mV})$ and bare surface $(162 \mathrm{mV})$. The biocomposite acts as barrier molecules and blocking the surfaces of SS304 from corrosion [34]. The decreasing $\mathrm{I}_{\text {corr }}$ values were observed at 24-96 h. The protective coating forms on the surface of SS304 by the active functional groups such as amino group $\left(-\mathrm{NH}_{2}\right)$ in gelatin and sulphates $\left(\mathrm{SO}_{4}{ }^{2-}\right)$ in $k$ Carrageenan polysaccharides. These active functional groups of biocomposite are enhancing the anticorrosive properties and efficiently catalyze the oxygen reduction on the metal surface. Generally, the Tafel plots have shown less $\mathrm{E}_{\text {corr }}$ values $(<85 \mathrm{mV})$ for biocomposites coated SS304, which indicates that the polysaccharide polymers could efficiently inhibit the anodic and cathodic reactions on the surface of SS304 [35]. 

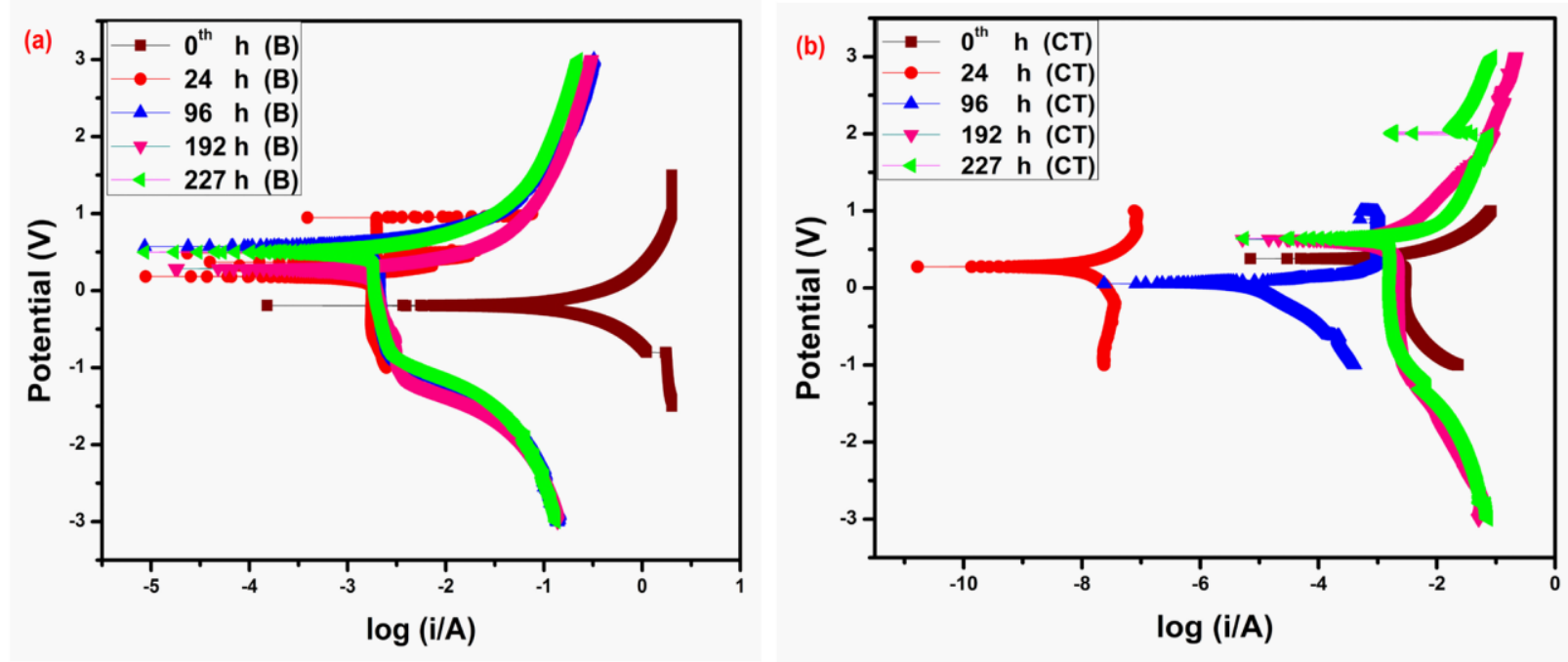

Fig.3. (a) Potententiodynamic polarization curve for bare SS and b) biocomposite coated SS 304, respectively.

\subsection{Impedance spectroscopic analysis}

The corrosion inhibition efficiency was further confirmed by electrochemical impedance spectroscopic technique (EIS) using CHI 760-CH, USA, Instruments with Z SimpWin software. The adsorption of biocomposite as film on the surface is represented in Figure 4 (a and b). The Nyquist plots of bare and biocomposite coated SS304 showed the occurred short depressed semicircle on bare SS304 throughout the scan and a higher $\mathrm{R}_{\mathrm{ct}}$ value, which leads to obtain a long semicircle like graph for the coated SS304. The estimated corrosion inhibition efficiency of biopolymer coated SS304 is $65 \%$ at $227 \mathrm{~h}$, which indicates that the biopolymer coating acts as a proficient barrier between metal surface and the corrosive environment [36]. The obtained percentage of impedance efficiency (IE\%) is calculated according to Eq. (1) with the observed impedance results. 

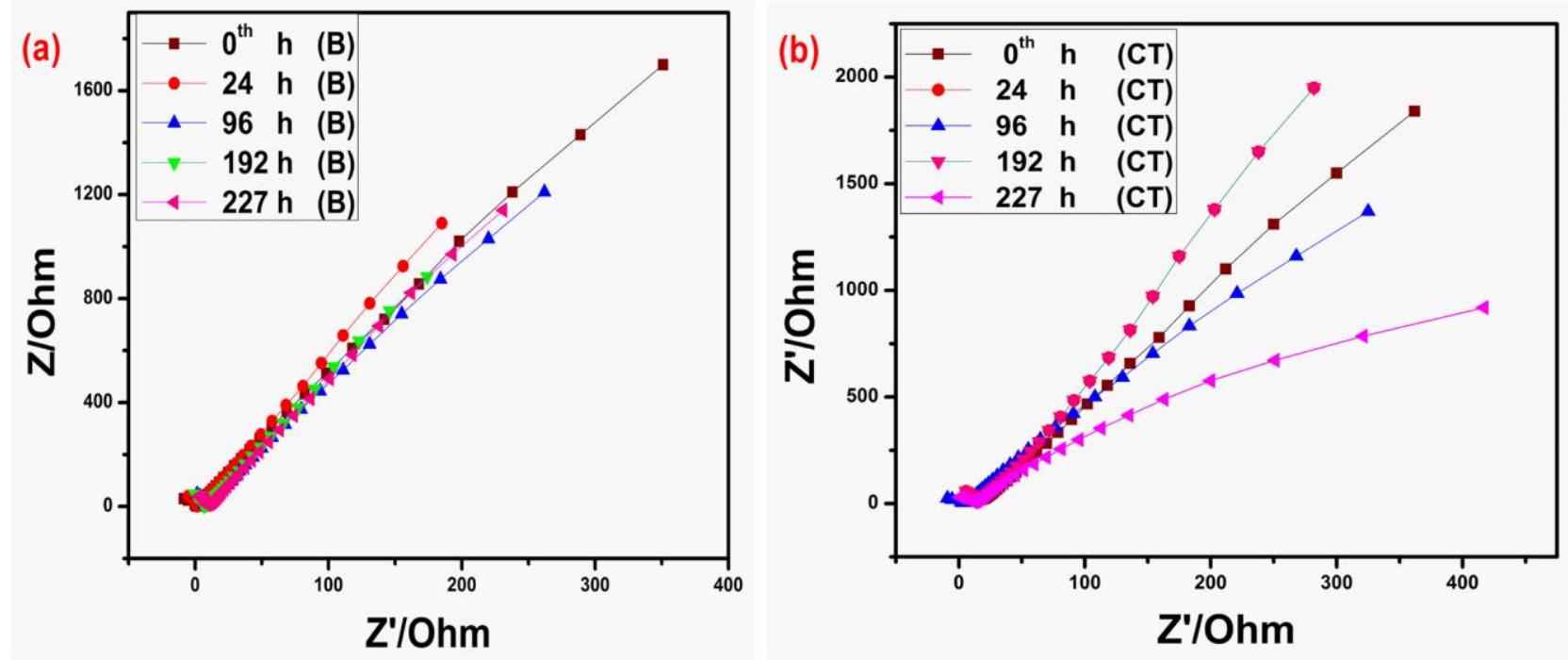

Fig.4 a) EIS (Nyquist plot) data of bare SS 304 and b) biocomposite coated SS 304, respectively.

The highest $\mathrm{R}_{\mathrm{ct}}$ value $\left(1238.5 \Omega \mathrm{cm}^{2}\right.$ ) was observed for biocomposite coated film, the corrosion rate was controlled by the charge transfer process. Where $\mathrm{R}_{\mathrm{ct}}(\mathrm{CT})$ and $\mathrm{R}_{\mathrm{ct}}(\mathrm{B})$ are the charge transfer resistances in biocomposite coated and bare SS304 respectively in $3.5 \% \mathrm{NaCl}$ electrolyte. Roman et al., has reported passive layer formation on the surface of steel indicates the increased $R_{c t}$ values [37]. The increased $R_{c t}$ values was noted $\left(1238 \Omega \mathrm{cm}^{2}\right)$ at $24 \mathrm{~h}$, which indicates the passive layer formation and the corrosion inhibition efficiency was also noted as $97 \%$ and $65 \%$ inhibition efficiency was observed in $227 \mathrm{~h}$. The decreased $\mathrm{R}_{\mathrm{ct}}$ values was (1052 $\Omega \mathrm{cm}^{2}$ ) noted at $192 \mathrm{~h}$, indicates the breakdown of passive layer and the diffusion of chloride ions into the surface [38]. Literature noted the increased charge transfer resistance $\left(R_{c t}\right)$ was observed with increased concentrations of gelatin inhibitor. Gelatin is a good corrosion inhibitor, it forms a film on the surface of carbon steel, which protect the metal from the corrosion media [39]. The observed electrochemical impedance results denoted that the increased diameter of semicircle directly indicates the resistance of the sample. Corrosion resistance controlled by single charge transfer process [40]. The Nyquist plots obtained with increasing diameter indicate the response carrageenan and inulin biopolymer inhibitors.

\subsection{Mechanism of corrosion inhibition}

The obtained results showed that the proposed $\boldsymbol{k}$-Carrageenan based hybrid composite with gelatin shows a remarkable inhibition efficiency towards the medical grade stainless steel 304 from the corrosive environment, attributed to their gel forming ability. The presence of 
oxygen and electrostatically negative half-ester sulphate groups are strongly anionic and comparable to inorganic sulphate ions. These may serve as adsorption centres in the prepared composite which causes for the enhanced inhibition efficiency [9]. The obtained large passive domain of mild steel obtained by polarization curves in $0.5 \mathrm{~mol} / \mathrm{dm}^{3}$ of $\mathrm{NaCl}$ containing nitrate ions at basic $\mathrm{pH}$ suggests the presence of $\mathrm{Fe}(\mathrm{II})$ oxides/hydroxides, as $\mathrm{Fe}_{3} \mathrm{O}_{4}$ and $\mathrm{Fe}(\mathrm{OH})_{2}$. The $\mathrm{SO}_{4}{ }^{2-i o n s}$ are fascinated by the charges on the metal surface which tends to be charged negatively. The obtained results could be explained on the hypothesis that the negatively charged $\mathrm{SO}_{4}{ }^{2-}$ would attach to the positively charged metal surface. Such positively surface can electrostatically attract the negatively charged sulphate ions and the partial negatively charged oxygen heteroatoms of $\boldsymbol{k}$-Carrageenan yields as adsorbed layer on the metal surface [41]. Schematic representation of adsorption of $\boldsymbol{k}$-Carrageenan on mild steel surface is shown in Figure 5. Moreover, the gelatin molecules are anticipated to adsorb on the steel surface by an interaction with its nitrogen and oxygen atoms on the metal surface to form a metal/gelatin complex on the metal surface, which also facilitated the formation of $\boldsymbol{k}$ Carrageenan based hybrid composite as a layer, which protects the steel from the corrosive environment under the experimental conditions [42].
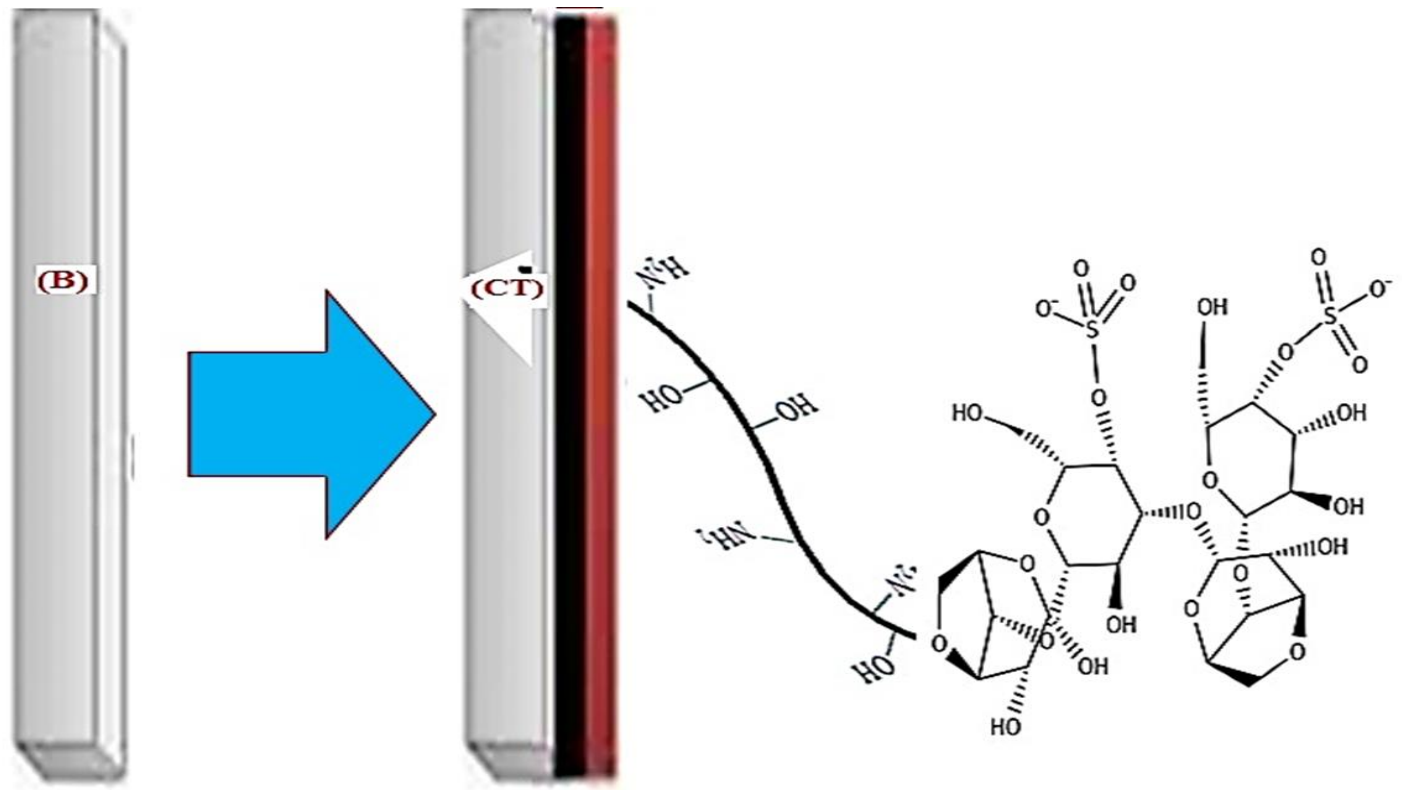

Fig.5.Mechanism of corrosion inhibition by $k$-Carrageenan-gelatin biocomposite

\subsection{Surface morphology analysis}

\subsubsection{Scanning electron microscopy}

As illustrated in Figure 6, the subsequent surface morphological changes of the bare SS304 
and biocomposite coated thin films have shown smooth and devoid shapes on before and after the electrochemical studies with $3.5 \mathrm{wt} . \%$ of $\mathrm{NaCl}$.
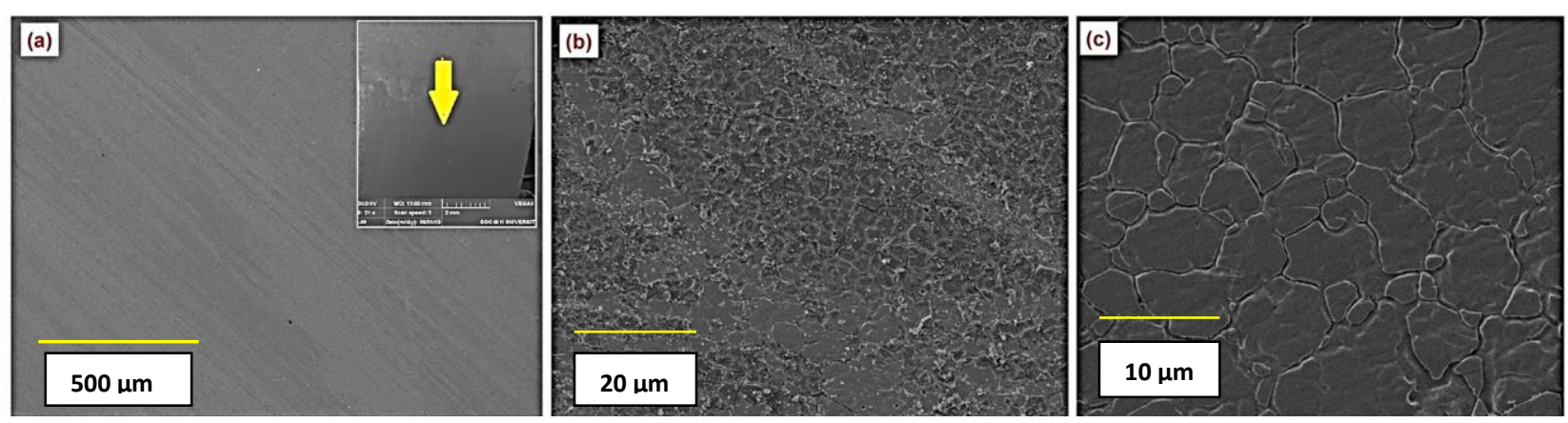

Fig. 6. SEM images of surface degradation of SS304 exposed to 3.5\% NaCl electrolyte (a) biocomposite coated SS304 (inset image denotes the coating direction of SS304) (b) biocomposite coated SS 304 exposed to $3.5 \%$ $\mathrm{NaCl}$ electrolyte at $227 \mathrm{~h}$ (c) bare SS 304 exposed to $3.5 \% \mathrm{NaCl}$ electrolyte solution at $227 \mathrm{~h}$.

The inset in Figure 6a depicts the carrageenan-gelatin coating direction on SS304. The observed morphological changes on SS304 indicates that the efficiency of barrier protective effect of biocomposite on coated SS304 (Figure 6b). The surface shows the deteriorate etched and devoid pitting on the surface damge after the immersion for biocomposite coated surface at $227 \mathrm{~h}$. While, the bare surface of SS304 showed major scratches and severe damages with devoid pitting corrosion on the surfaces. These observed results confirm that the proposed novel biocomposite system acts as an effective barrier in protecting the SS304 in order to prevent penetration of ions and electrolyte into the steel sample [43].

\subsubsection{AFM analysis}

Figure 7 shows the surface morphology of three dimensional (3D) cross sectional AFM images of bare and biocomposite coated SS304. The surface roughness was calculated from the deviations in height to the profile mean value [44]. The surface of bare SS304 clearly shows a higher roughness value then biocomposite coated SS304 (Figure 7a). The estimated average roughness value for bare SS304 is $77.07 \mathrm{~nm}$ and the biocomposite coated surface roughness value is $49.61 \mathrm{~nm}$. The bare SS304 was effectively affected by the $\mathrm{NaCl}$ ions, due to their ease diffusion on the surface (see details on Figure 7 (a-b) $[45,46]$. The lower roughness values of biocomposite coated SS304 indicated an increase on the surface protectiveness under the corrosive environment. 

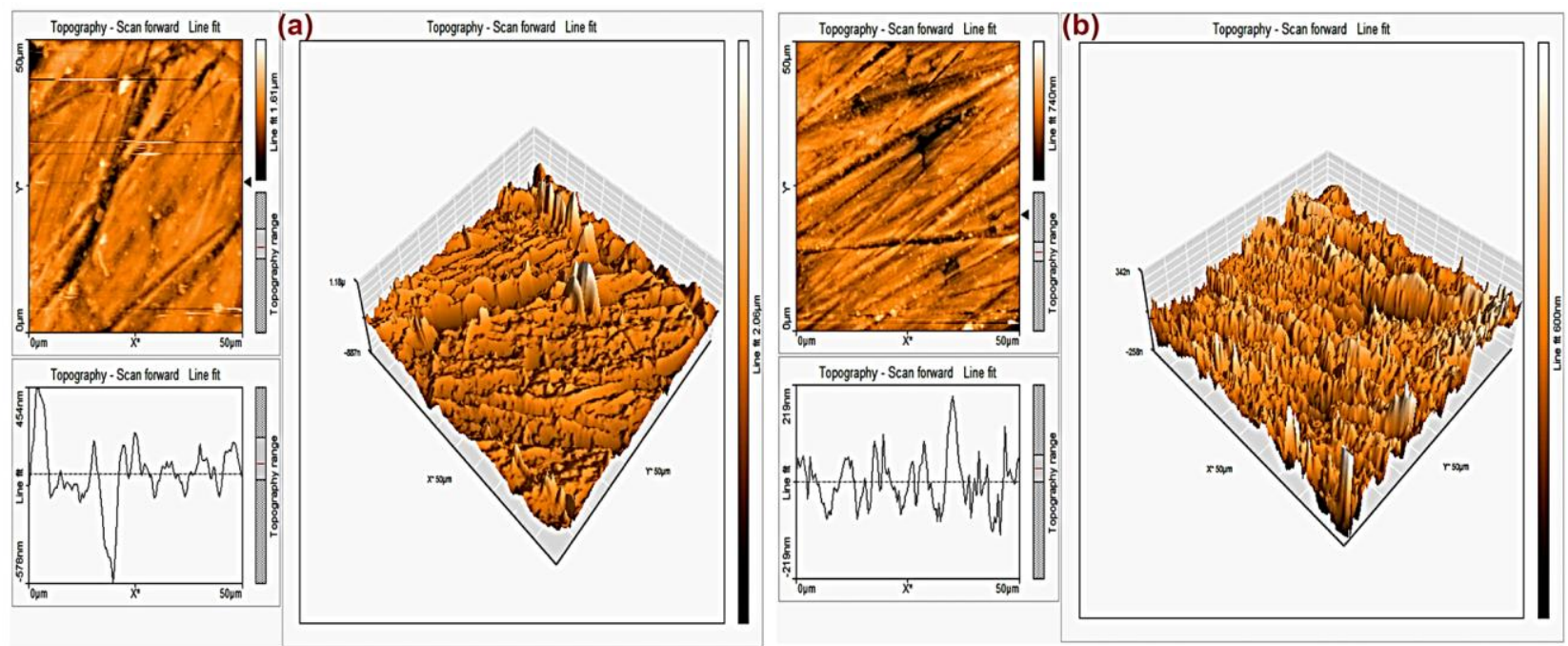

Fig.7. AFM images of (a). bare SS304.and (b) biocomposite coated SS304 after exposing 227h.

\section{Conclusions}

This novel study was focused to improve the surface of SS304 creating self-assembled multilayer coating using a gelatin cross-linked $\boldsymbol{k}$-Carrageenan film. Its corrosiveness efficiency was evaluated by applying electrochemical technique in $3.5 \mathrm{wt}$ \% of $\mathrm{NaCl}$ electrolyte. The observed two positive potentials at $87.29 \mathrm{mV}(73 \mathrm{~h})$ and $134 \mathrm{mV}(225 \mathrm{~h})$ for the biocomposite coated SS304 confirms its enhanced inhibiting property when compared to the bare specimen. The bare specimen showed lower potentials at -14.309 and $82.59 \mathrm{mV}$. Almost $65 \%$ higher corrosion inhibition efficiency were obtained with $\boldsymbol{k}$-Carrageenan-gelatin composite by using potentiodynamic polarization, electrochemical impedance spectroscopy and open circuit potential analysis in $3.5 \mathrm{wt} \% \mathrm{NaCl}$. Further, the $\mathrm{I}_{\text {corr }}$ values from Tafel plot indicated lower values obtained for bare SS 304 subject5ed to longer time. It is concluded that the steel with biocomposite coating enabled better (above 95\% corrosion inhibition efficiency) at the very beginning of the test. This may suggest that the biocomoposite material with anticorrosive ability can be used as corrosion inhibitors, but the coating do not last for a long period when subjected to corrosion. Further a significant difference was noted when was compared the morphological structure of the bare and coated SS304 one. The AFM images revealed a decreased surface roughness for SS304 coated (i.e. $49.61 \mathrm{~nm}$ ). The Scanning Electron Microscopic images indicated the occurrence of voids/cracks on the surface of bare SS304 while on the biopolymer coated SS304 were noted only mild pitting on the surface. The obtained results confirmed that the biopolymer composite $\boldsymbol{k}$-Carrageenangelatin acts as a good protective film against corrosion progression. This novel coating 
represents a cost-effective solution and act as an efficient corrosive inhibitor in practical usages. In the future, in order to further endorse the benefits of proposed coating (kCarrageenan-gelatin) we want to verify its characteristics against recent coating materials proposed in the literature as anticorrosive agents for biomedical implants (see details of potential coatings in Table 3). 
Table 3. Different coating materials as anticorrosive agents

\begin{tabular}{|c|c|c|}
\hline S.No & $\begin{array}{l}\text { Name of coating materials used for corrosion } \\
\text { protection in biomedical applications }\end{array}$ & References \\
\hline 1. & Polydopamine Biopolymer & [47] \\
\hline 2. & $\begin{array}{l}\text { Poly(lactic acid) } \\
\text { and fluorine-doped hydroxyapatite }\end{array}$ & [48] \\
\hline 3. & Calcium phosphate & {$[49]$} \\
\hline 4. & Hydroxyapatite & {$[50]$} \\
\hline 5. & Antibacteiral coating & {$[51]$} \\
\hline 6. & $\begin{array}{l}\text { Silver-doped } \\
\text { antibacterial CDHA }\end{array}$ & {$[52]$} \\
\hline 7. & MAO/PLA & {$[53]$} \\
\hline 8. & Sodium Alginate & {$[54]$} \\
\hline 9. & Pectin-grafted polyacrylamide & {$[55]$} \\
\hline 10. & $\begin{array}{l}\text { Polydopamine/dicalcium } \\
\text { phosphate dihydrate/collagen composite }\end{array}$ & {$[56]$} \\
\hline 11. & $\mathrm{Mg} 2 \mathrm{Ca}$ & {$[57]$} \\
\hline 12. & Hydroxide/poly-dopamine composite & {$[58]$} \\
\hline 13. & Polydopamine/liposome & {$[59]$} \\
\hline 14. & $\begin{array}{l}\text { Dicalcium phosphate dihydrate/poly(lactic-co- } \\
\text { glycolic acid) hybrid coating }\end{array}$ & {$[60]$} \\
\hline 15. & Poly(aniline-co-o-toluidine) copolymer & {$[61]$} \\
\hline 16. & $\begin{array}{l}\text { Graphene }+\mathrm{CeO} 2 \\
+ \text { polyurethane }\end{array}$ & {$[62]$} \\
\hline 17. & $\begin{array}{l}\text { Graphene } \\
+ \text { polystyrene }\end{array}$ & {$[63]$} \\
\hline 18. & $\mathrm{Ni}-\mathrm{Zn}-\mathrm{TiO} 2$ & {$[64]$} \\
\hline 19. & Nanocomposite coating & {$[65]$} \\
\hline 20. & Nanostructured chromium coatings & {$[66]$} \\
\hline 21. & Polyurethane nanocomposite & {$[67]$} \\
\hline 22. & $\begin{array}{l}\text { Polydimethylsiloxane-titania nanocomposite } \\
\text { coating }\end{array}$ & {$[68]$} \\
\hline 23. & Nano-hybrid & [69] \\
\hline
\end{tabular}


epoxy as protective marine coatings

24. Titania and alumina nanoparticles sol-gel coating [70]

25. Polyurethane composite [71]

\section{Acknowledgments}

L. Muthulakshmi acknowledges the Department of Science and Technology-Science and Engineering Research Board Government of India, for the award of a National Postdoctoral Fellowship (PDF/2017/001574). The authors acknowledge the financial assistance of DSTPURSE -MKU for the SEM facility.

\section{References}

1. Swarnima Singh, Krishna Kant Pandey, Aminul Islam, Anup Kumar Keshri (2020) Corrosion behaviour of plasma sprayed graphene nanoplatelets reinforced hydroxyapatite composite coatings in simulated body fluid, Ceramics International. 0272-8842 https://doi.org/10.1016/j.ceramint.2020.02.139

2. Chraibi, M Antibacterial activity and corrosion inhibition of mild steel in $1.0 \mathrm{M}$ hydrochloric acid solution by M. piperita and M. pulegium essential oils (2017) Journal of Materials and Environmental Sciences 8 3: 972-981.

3. Geethanjali R, Sabirneeza A.A.F, Subhashini S (2014) Antibacterial activity and corrosion inhibition of mild steel in 1.0 M hydrochloric acid solution by M. piperita and M. pulegium essential oils, Indian Journal of Materials Science. http://dx.doi.org/10.1155/2014/356075.

4. Carlucci MJ, Pujol CA, Clancia M, Noseda MD, Matulewicz MC, Damonte EB and Cerezo AS (1997) Antiherpetic anticoagulant properties of carrageenans from the red seaweed Gigartina skottsbergii and their cyclized derivatives: correlation between structure and biological activity. Internatl J Biol Macromol 20: 97 - 105.

5. Emanuel Airton de Oliveir Farias , Marianne Corrêa dos Santos, Natália de Araujo Dionísio, Patrick V, Quelemes, José Roberto de Sousa Almeida Leite, Peter Eaton, Durcilene Alves da Silva , Carla Eiras Layer-by-Layer films based on biopolymers extracted from red seaweeds 
and polyaniline for applications in electrochemical sensors of chromium VI, (2015) Materials Science and Engineering B. 0921-5107.

6. Garcia Tasende, Manríquez-Hernandez J A Carrageenan properties and applications: a review. In: Pereira L (ed.) Carrageenans: sources and extraction methods, molecular structure, bioactive properties and health effects (2016) Nova Science Publishers New York 17-50.

7. Umoren S A, Eduok U M Application of carbohydrate polymers as corrosion inhibitors for metal substrates in different media: A review (2016) Carbohydrate Polymers. 140 : 314-341.

8. Geethanjali R, Sabirneeza AF, Subhashini S Investigation of Corrosion Inhibition Efficiency of Some Synthesized Water Soluble Terpolymers on N-80 Steel in $\mathrm{HCl}, \mathrm{NaCl}$ and Simulated Oil Well Water, (2014) Indian Journal of Material Science 1-9 : 356075.

9. J.Necas, Bartosikova L Carrageenan: A Review (2013) Veterinarni Medicina. 58 :(4) 187205.

10. Thangaraj, Balusamy A facile method to modify the characteristics and corrosion behavior of 304 stainless steel by surface nanostructuring toward biomedical applications. (2015) ACS applied materials \& interfaces. 7 32: 17731-17747.

11. Stankiewicz A, Jagoda Z, Zielinska K, Szczygieł I, Gelatin microgels as a potential corrosion inhibitor carriers for self-healing coatings: preparation and co deposition, Mater. Corros. (2015) Mater. Corros. 66:1391-1396.

12. Mobin M, Tanveer N Corrosion performance of chemically synthesized poly (aniline-co-otoluidine) copolymer coating on mild steel. (2012) J. Coat. Tech. \& Res. $9: 27$ - 38.

13. Zheludkevich M L, Tedim J, Ferreira M G S "Smart" coatings for active corrosion protection based on multi-functional micro and nanocontainers, (2012) Electrochimica Acta. 81: 314323.

14. Toshiaki Ohtsuka. Corrosion Protection of Steels by Conducting Polymer Coating, (2012) International Journal of Corrosion 7: 915090.

15. Mohammad M. Fares M, Maayta A K, Jamil A, Al-Mustafa Corrosion inhibition of iotacarrageenan natural polymer on aluminum in presence of zwitterion mediator in $\mathrm{HCl}$ media, (2012) Corrosion Science. 65: 223-230.16. 
16. Grozea CM, Walker CG, Approaches in designing non-toxic polymer surfaces to deter marine biofouling (2009) Soft Matter 5 21: 4088-4100.

17. Gowraraju ND, Jagadeesan S, Ayyasamy K Olasunkanmi L O, Ebenso E E Subramanian C Adsorption characteristics of Iota-carrageenan and Inulin biopolymers as potential corrosion inhibitors at mild steel/sulphuric acid interface, (2017) Journal of Molecular Liquids 232: 919.

18. Maruthupandian A, Geethambiga P, Saranya K, Thangavel P Bioactive Potential of Red Seaweed (Rhodophyceae) Against Human Pathogenic Bacteria. (2015) Int J Eng Technol Sci Res. 1(5):44-48.

19. Qian PY, Xu Y, Fusetani N Natural products as antifouling compounds: recent progress and future perspectives (2010) Biofouling 26: 223-234.

20. Jakir Hossan Md, Gafur M A,Kadir M R, Mohammad Mainul Karim Preparation and characterization of gelatin-hydroxyapatite composite for bone tissue engineering (2014) Int J eng technol. 14:24-32.

21. Abdolahi A, Hamzah E, Ibrahim Z, And Hashim S, Application of EnvironmentallyFriendly Coatings Toward Inhibiting the Microbially Influenced Corrosion (MIC) of Steel: A Review, (2014) Polymer Reviews. 54:702-745.

22. Uros maver, Klodian Xhanari, Marko Zizek, Dorota Korte, Lidija Gradišnika, Mladen, Franko A combination of interdisciplinary analytical tools for evaluation of multi-layered coatings on medical grade stainless steel for biomedical applications (2018) European Journal of Pharmaceutics and Biopharmaceutics. S0939-6411 12757.

23. Yang W J, Neoh K G, Kang E T, Teo SL, Rittschof D Polymer brush coatings for combating marine biofouling (2014) Prog. Polym. Sci. 39:1017-1042.

24. Ayatta A M, El-Mahdy G A Al-Lohedan HA, El-Saeed A M Preparation and application of crosslinked poly (sodium acrylate)-coated magnetite nanoparticles as corrosion inhibitor for carbon steel alloy, Molecules. (2015) Molecules. 20 1244-1261.

25. Wu G, Li P, Feng H, Zhang X, Chu PK. J Engineering and functionalization of biomaterials via surface modification (2015) Mater Chem B. 3 (10): 2024-42. 
26. Pal A, Dey S, Sukul D Effect of temperature on adsorption and corrosion inhibition characteristics of gelatin on mild steel in hydrochloric acid medium (2016) Res. Chem. Intermed. 42: 4531-4549.

27. Gomaez E,Ruprez O.P, FTIR-ATR spectroscopy as a tool for polysaccharide identification in edible brown and red seaweeds, (2011) Food Hydrocolloids. 25(6):1514-1520.

28. Hossan J, Gafur M A, Kadir M R M. Mainul Preparation and characterization of gelatinhydroxyapatite composite for bone tissue engineering, (2014) Int. J. Eng. Technol 14:24-32.

29. Haruna K, Obot I B, AnkahN K, Sorour A A SalehT A, Gelatin: A green corrosion inhibitor for carbon steel in oil well acidizing environment (2018) Journal of Molecular Liquids. 264:515-525.

30. Umoren S A, Ogbobe O, Igwe I O, Ebenso E E, Inhibition of mild steel corrosion in acidic medium using synthetic and naturally occurring polymers and synergistic halide additives, (2008) Corrosion Science. 50 :1998-2006.

31.WenjinY, Wee Kit Ong, Linda Yongling W, Sudesh L. Wijesinghe. Inhibition of mild steel corrosion in acidic medium using synthetic and naturally occurring polymers and synergistic halide additives, (2019) Coatings. 9:52.

32. Dinesh Kumar D Gobi Saravanan Kaliaraj. Multifunctional zirconium nitride/copper multilayer coatings on medical grade $316 \mathrm{~L}$ SS and titanium substrates for biomedical applications, Journal of the Mechanical Behavior of Biomedical Materials. http://dx.doi.org/10.1016/j.jmbbm.2017.09.007

33. El-Haddad M N Hydroxyethyl cellulose used as an eco-friendly inhibitor for 1018 c-steel corrosion in 3. 5\% NaCl solution (2014) Carbohydrate Polymers. 112: 595-602.

34. Shih-Chen Shi, Chieh-Chang Su. Corrosion Inhibition of High Speed Steel by Biopolymer HPMC Derivatives (2016) Materials. 9: 612.

35. Ferreira E S, Giancomelli C, Spinelli A Evaluation of the inhibitor effect of 1-ascorbic acid on the corrosion of mild steel, (2004) Mater. Chem. Phys. 1:129-134.

36. Amin M A, Mohsen Q, Hazzazi Q A, Synergistic effect of I-ions on the corrosion inhibition of $\mathrm{Al}$ in 1.0M phosphoric acid solutions by purine (2009) Mater. Chem. Phys. 114 (2009) 908-914. 
37. Roman D,Bernardi J C, Boeira C D, Souza De F S, Spinelli A, Figueroa C A, R.L.O. Basso R LO Nanomechanical and electrochemical properties of $\mathrm{ZrN}$ coated NiTi shape memory alloy (2012) Surf Coat Technol 206:4645-4650.

38.Haruna I B, Obot N K, Ankah A A, Sorour T A, Saleh Gelatin: A green corrosion inhibitor for carbon steel in oil well acidizing environment (2018) Journal of Molecular Liquids. 264 (2018) 515-525.

39. Wang B, Du M, Zhang J, Gao C J Electrochemical and surface analysis studieson corrosion inhibition of Q235 steel by imidazoline derivative against CO2 corrosion (2011) Corrosion Science 53: 353-361.

40.Shanmugam S, Manavallan R Venkappayya D, Sundaramoorthy K Mounnissamy V M, S. Hemalatha S, Ayyappan T Natrual Polymers and their applications (2005) Radiance 4 :478481.

41. Saranya J, Sounthari P, Kiruthuka A, Parameswari K, ChitraS The inhibiting effect of some quinoxaline derivative towards mild steel corrosion in acid media: Chemical, electrochemical and theoretical studies (2015). Journal of Materials and Environmental Science. 6: 425-444.

42. Honarvar Nazari M, Shi X Hosseini M, Makhlouf A S H Polymer-based nanocomposite coatings for anticorrosion applications. (2016) (Eds.), Springer Publishing, DOI: 10.1007/978-3-319-26893-418: 373-399.

43. Pal A Dey S, Sukul D Effect of temperature on adsorption and corrosion inhibition characteristics of gelatin on mild steel in hydrochloric acid medium (2016) Res. Chem. Intermed. 42: 4531-4549.

44. Megha Basik, Mohammad Mobin \& Mohd Shoe Cysteine-silver-gold Nanocomposite as potential stable green corrosion inhibitor for mild steel under acidic condition. (2020) Scientific Reports. 10: 279.

45. Subramanian B, Dhandapani P, Maruthamuthu S, Jayachandran M Biosynthesis of calcium hydroxylapatite coating on sputtered $\mathrm{Ti} / \mathrm{TiN}$ nano multilayers and their corrosion behavior in simulated body solution (2010) J Biomater Appl. 26: 687-705. 
46. Obot I B, Ikenna B, Onyeachu A, Madhan Kumar Sodium alginate: A promising biopolymer for corrosion protection of API X60 high strength carbon steel in saline medium (2017) Carbohydrate Polymers. 178:200-208.

47. Farshad Bahremand, Taghi Shahrabi, Bahram Ramezanzadeh., Construction of an excellent eco-friendly anti-corrosion system based on epoxy@Sm2O3-polydopamine biopolymer on the mild steel surface., Journal of the Taiwan Institute of Chemical Engineers 000 (2020) 112.

48. Prabaha Sikder, Yufu Ren, Sarit B. Bhaduri, Synthesis and evaluation of protective poly(lactic acid) and fluorine-doped hydroxyapatite-based composite coatings on AZ31 magnesium alloy.,Journal of Materials Research., DOI: 10.1557/jmr.2019.317.

49. S. Shadanbaz and G.J. Dias: Calcium phosphate coatings on magnesium alloys for biomedical applications: A review. Acta Biomater. 8, 20 (2012).

50. R.G. Guan, I. Johnson, T. Cui, T. Zhao, Z.Y. Zhao, X. Li, and H. Liu: Electrodeposition of hydroxyapatite coating on $\mathrm{Mg}-4.0 \mathrm{Zn}-1.0 \mathrm{Ca}-0.6 \mathrm{Zr}$ alloy and in vitro evaluation of degradation, hemolysis, and cytotoxicity. J. Biomed. Mater. Res., Part A 100, 999,(2012).

51. Sarit B Bhaduri, Vijay K Goel, Yufu Ren, Prabaha Sikder., Bifunctional bioactive antibacterial coatings, and process for coating implant surfaces therewith., 15/946,851, 2018 .

52. P. Sikder, N. Koju, Y. Ren, V.K. Goel, T. Phares, B. Lin, and S.B. Bhaduri: Development of single-phase silver-doped antibacterial CDHA coatings on Ti6Al4V with sustained release.Surf. Coat. Technol. 342, 105 (2018).

53. R-C. Zeng, W-C. Qi, Y-W. Song, Q-K. He, H-Z. Cui, and E-H. Han: In vitro degradation of MAO/PLA coating on Mg-1.21Li-1.12Ca-1.0Y alloy. Front. Mater. Sci. 8, 343 (2014).

54. I.B. Obota, Ikenna B. Onyeachu, A.Madhan Kumar., Sodium alginate: A promising biopolymer for corrosion protection of API X60 high strength carbon steel in saline medium., Carbohydrate Polymers 178 (2017) 200-208.

55. Geethanjali, R., Sabirneeza, A. A. F., \& Subhashini, S. (2014). Water-Soluble and biodegradable pectin-grafted polyacrylamide and pectin-grafted polyacrylic acid: electrochemical investigation of corrosion-inhibition behaviour on mild steel in $3.5 \%$ $\mathrm{NaCl}$ media. Indian Journal of Materials Science. http://dx.doi.org/10.1155/2014/356075.

56. Yunting Guo, Siqi Jia, Lu Qiao, Yingchao Su, Rui Gu, Guangyu Li, Jianshe Lian., Enhanced corrosion resistance and biocompatibility of polydopamine/dicalcium phosphate 
dihydrate/collagen composite coating on magnesium alloy for orthopaedic applications., Journal of Alloys and Compounds, S0925-8388(19)34028-9.

57. Z.-Y. Ding, L.-Y. Cui, X.-B. Chen, R.-C. Zeng, S.-K. Guan, S.-Q. Li, F. Zhang, Y.-H. Zou, Q.-Y. Liu, In vitro corrosion of micro-arc oxidation coating on Mg-1Li-1Ca alloy The influence of intermetallic compound Mg2Ca, J. Alloys Compd., 764 (2018) 250-260.

58. H. Li, F. Peng, D. Wang, Y. Qiao, D. Xu, X. Liu, Layered double hydroxide/polydopamine composite coating with surface heparinization on $\mathrm{Mg}$ alloys: improved anticorrosion, endothelialization and hemocompatibility, Biomater. Sci., 6 (2018) 18461858.

59. M.E. Lynge, R. Ogaki, A.O. Laursen, J. Lovmand, D.S. Sutherland, B. Stadler, Polydopamine/liposome coatings and their interaction with myoblast cells, ACS Appl. Mater. Interfaces, 3 (2011) 2142-2147.

60. X. Li, Z. Weng, W. Yuan, X. Luo, H.M. Wong, X. Liu, S. Wu, K.W.K. Yeung, Y. Zheng, P.K. Chu, Corrosion resistance of dicalcium phosphate dihydrate/poly(lactic-co-glycolic acid) hybrid coating on AZ31 magnesium alloy, Corros. Sci., 102 (2016) 209-221.

61. Mobin, M. and Tanveer, N.: Corrosion performance of chemically synthesized poly(aniline-co-o-toluidine) copolymer coating on mild steel. J. Coat. Tech. \& Res. 9 (2012) 27 - 38. DOI:10.1007/s11998-011-9328.

62. Rahman MM. A Promising coating of nanostructured graphene-ceria nanofillers in polyurethane for corrosion protection. In: NACE U6 conference proceeding, 26-30, 2017, New Orleans, USA.

63. $\mathrm{Yu} \mathrm{Y-H,} \mathrm{et} \mathrm{al.} \mathrm{High-performance} \mathrm{polystyrene/graphenebased} \mathrm{nanocomposites} \mathrm{with}$ excellent anti-corrosion properties. Polym Chem 2014; 5: 535-550.

64. Katamipour A, Farzam M and Danaee I. Effects of sonication on anticorrosive and mechanical properties of electrodeposited $\mathrm{Ni}-\mathrm{Zn}-\mathrm{TiO} 2$ nanocomposite coatings. Surf Coat Technol 2014; 254: 358-363.

65. AV Radhamani, Hon Chung Lau and S Ramakrishna., Nanocomposite coatings on steel for enhancing the corrosion resistance: A review., Journal of Composite Materials 0(0) 121.

66. Lin J and Dahan I. Nanostructured chromium coatings with enhanced mechanical properties and corrosion resistance. Surf Coat Technol 2015; 265: 154-159.

67. Joshi M, Adak B and Butola BS. Polyurethane nanocomposite based gas barrier films, membranes and coatings: a review on synthesis, characterization and potential applications. Progr Mater Sci 2018; 97: 230-282. 
68. Cui $X$, et al. Polydimethylsiloxane-titania nanocomposite coating: fabrication and corrosion resistance. Polymer 2018; 138: 203-210.

69. Atta AM, et al. Application of magnetite nano-hybrid epoxy as protective marine coatings for steel. RSC Adv 2015; 5: 101923-101931.

70. Ershad-Langroudi A, Abdollahi $\mathrm{H}$ and Rahimi A. Mechanical properties of sol-gel prepared nanocomposite coatings in the presence of titania and aluminaderived nanoparticles. Plast Rubber Compos 2017; 46:25-34.

71. El Saeed AM, El-Fattah MA and Azzam AM. Synthesis of ZnO nanoparticles and studying its influence on the antimicrobial, anticorrosion and mechanical behavior of polyurethane composite for surface coating. Dyes Pigment 2015; 121: 282-289. 